\title{
Thermal Energy Storage System Using Pykrete
}

\author{
Alisha Vijay Supekar ${ }^{1}$, Divyashree Prasad Deore ${ }^{2}$, Sarthak Sharma ${ }^{3}$ \\ B.E. Mechanical Engineering, Sinhgad Academy of Engineering, Pune, Maharashtra, India
}

\begin{abstract}
In this paper, a special design of an experimental rig was used to study and evaluate the performance of using the Pykrete thermal storage capacity for cooling purpose. Nowadays ice thermal storage system is mostly used because it is practical due to the large heat of fusion of ice to change into water. Since Pykrete has a slower melting rate than that of ice, we have conducted test on Pykrete to evaluate its viability as an alternative cooling material to ice in TES. Thermal storage techniques have provided opportunities to store cooling energy in ice when the power price is relatively low and hence it is expected that Pykrete will give similar results. The experimental rig that was built is a simple domestic air conditioning prototype that can be used to cool small spaces with Pykrete bank which was prepared for this purpose. The Pykrete storage capacity process is an effective process of using chillers or refrigeration plant to build ice during off-peak hours to serve part or the entire on-peak cooling requirement.
\end{abstract}

Keywords: Air conditioning, Coefficient of Performance, Pykrete, Thermal Energy Storage System.

\section{Introduction}

Refrigeration: Refrigeration can be defined as the process of removing heat from any substance which may be a solid, a liquid, or a gas; it maintains the temperature of the substance below that of its surroundings. Refrigeration is therefore the science of moving heat from low temperature to high temperature. There are two common methods of refrigeration; these methods are natural and mechanical. In the mechanical refrigeration a refrigerant which is a substance capable of transferring heat that it absorbs at low temperatures and pressures to a condensing medium. By means of expansion, compression, and a cooling medium, such as air or water, the refrigerant removes heat from a substance and transfers it to the cooling medium. In the natural refrigeration, ice has been used in refrigeration since ancient times and it is still widely used. In this natural technique, the forced circulation of air or water passes around blocks of ice. Some of the heat of the circulating air is transferred to the ice, thus cooling the air, particularly for air conditioning applications.

Natural ice refrigeration: In natural ice refrigeration, cooling is accomplished by melting ice. Owing to its melting point of $\left(0{ }^{\circ} \mathrm{C}\right)$, Ice is used as an effective cooling agent because to melt it, ice must absorb $333.55 \mathrm{~kJ} / \mathrm{kg}$ (about 144 $\mathrm{Btu} / \mathrm{lb}$ ) of heat. This method is used for small-scale refrigeration such as in laboratories and workshops, or in portable cooler, and foodstuff maintained near this temperature have an increased storage life.

Pykrete: Pykrete is a frozen composite material made of approximately 14 percent sawdust or some other form of wood pulp (such as paper) and 86 percent ice by weight (6 to 1 by weight). During World War II, Geoffrey Pyke proposed it as a candidate material for a huge, unsinkable aircraft carrier for the British Royal Navy. Pykrete has some interesting properties including its relatively slow melting rate because of low thermal conductivity.

Sustainable cooling with thermal energy storage: Thermal energy storage (TES) is sometimes defined as a way of producing an energy sink or source, and provides methods and systems that allow storage of either cooling or heating produced at one period in time for later use at another period in time. TES results in two significant environmental benefits: (i) the conservation of fossil fuels through efficiency increases and/or fuel substitution, and (ii) reductions in emissions of such pollutants as $\mathrm{CO} 2, \mathrm{SO} 2$, NOx and CFCs. Thermal storage can either take the form of sensible heat storage (SHS) or latent heat storage (LHS). Latent heat storage is accomplished by changing a material's physical state whereas SHS is accomplished by increasing a material's temperature. Ice as (LHS) is one of the more common thermal storage materials used today. Ice provides one of the highest theoretical thermal storage densities (and, therefore, the lowest storage volumes). Ice systems have been shown to be excellent for smaller and even for some larger packaged installations. The annual electricity consumption for air conditioning systems can account for over than $30 \%$. Thus, stored energy for ice (focus on phase change) can be used instead of electricity when the demand for energy is high to reduce energy consumption in hot climates. Since Pykrete is more dense than as compared to ice (density of ice being $910 \mathrm{~kg} / \mathrm{cu} . \mathrm{m}$ and density of ice is $980 \mathrm{~kg} / \mathrm{cu} . \mathrm{m})$ Pykrete will take smaller volumes per kg mass as compared to ice. Also, Pykrete has a lower melting rate than ice so the time required to melt a given mass of Pykrete will be considerably higher than ice. Therefore, Pykrete can store thermal energy more effectively than ice. Hence a TES with Pykrete as a cooling medium should prove to be more efficient than ice.

\section{Research Goal}

The goal of this research is to carry out a study of cooling system performance through a simple domestic air conditioning prototype by using the Pykrete thermal storage capacity as an alternative method in air conditioning system for the following reasons:

1) To reduce the pollution and global warming by reducing the usage of oil fossil for producing electricity. With global warming, extremely hot weather may become more common, so, the ice thermal storage can provide potential solution for hot weather cooling issue and avoid forced shutdown during hot weather.

2) To benefit from the lower electricity charge during night time, the ice thermal storage technology is an essential 


\section{International Journal of Science and Research (IJSR) \\ ISSN (Online): 2319-7064}

Index Copernicus Value (2013): 6.14 | Impact Factor (2015): 6.391

solution, where part of the electricity consumption during peak hours at mid-day could be shifted to off-peak hours at night.

3) It can be used to cool building spaces when the main electrical power is blackout.

\section{Studies and Findings}

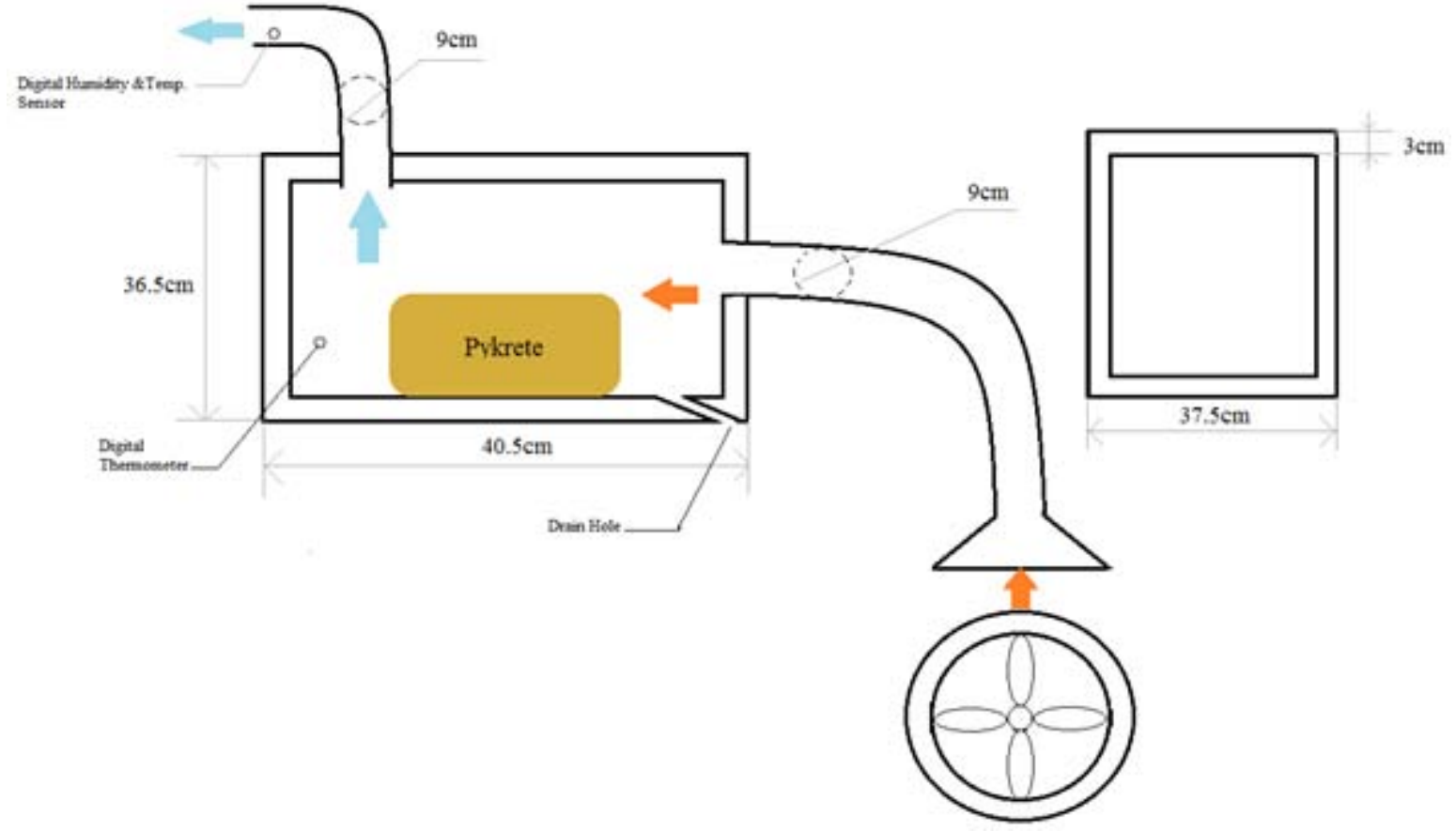

\section{A. Experimental Setup}

An experiment setup has been designed and fabricated to test feasibility of a Thermal Energy Storage System using Pykrete as shown in the schematic. The values were measured for inlet, outlet and box temperatures, relative humidity (ambient and outlet) and surface temperature of the Pykrete block. The rig consists of two units; power supply and cooling unit. The power supply provided was 220 volts, $50 \mathrm{~Hz}$ A.C. The cooling unit consists of Styrofoam box $\left(36.5 * 40.5 * 37.5 \mathrm{~cm}^{3}\right)$ of wall thickness $3 \mathrm{~cm}$. An inlet duct was provided on one of the side-walls of the box (Circular cross section, $9 \mathrm{~cm}$ diameter) and an outlet duct, same dimension as inlet duct, was provided on the top-lid of box. A drain hole of $0.5 \mathrm{~cm}$ diameter was provided on the base of the box. This setup was placed on a M.S. Frame fabricated using an L-angle with a taper of 1:15.125, to assist drainage melted water from the Pykrete block. The fan used is run by an A.C. motor with maximum rating of $70 \mathrm{~W}$.

Both the inlet and outlet ducts are PVC ducts used in air conditioning systems. Measuring instruments: The following measuring instruments were used;

1) Digital thermometers to measure the box and Pykrete surface temperatures.

2) Digital Humidity and Temperature sensors to measure ambient and outlet conditions.

\section{B. Theoretical Analysis}

1. Humidity Ratio: To measure the humidity ration of moist air $(\omega)$ which is the ratio of the mass of water vapor (Mw) to the mass of dry air (Ma)

$$
\omega=\frac{\mathrm{Mw}}{\mathrm{Ma}}=\frac{\mathrm{Ra}}{\mathrm{Rw}} \cdot \frac{\mathrm{Pw}}{\mathrm{Pat}-\mathrm{Pw}}
$$

$\mathrm{Ra}=$ gas constant for dry air $=0.2871 \mathrm{~J}^{\mathrm{kg}} \mathrm{kg}^{-1}$

$\mathrm{Rw}=$ gas constant for water vapour $=0.461 \mathrm{~J} \cdot \mathrm{kg}^{-1} \mathrm{~K}^{-1}$

$$
\omega=0.62198 \frac{\mathrm{Pw}}{\text { Pat }-\mathrm{Pw}}
$$

2. Air Pressure: To measure the air pressure, following equation is used:

$P a=P a t-P w \quad \ldots \ldots$... Na. $\mathrm{m}^{-2}$

$\mathrm{Pw}=$ vapour pressure at dew point temperature

3. Air Mass Flow Rate: Mass flow rate of air passing through the system can be calculated by measuring volume flow rate of air which is equal to:

$\mathrm{V}=A * v($ air $)$

$A=$ Cross sectional area of the inlet duct $\left(\mathrm{m}^{2}\right)$

$A=\frac{\pi}{4} * D_{\text {pipe }}^{2}$

$\mathrm{D}_{\text {pipe }}=$ diameter of inlet duct $(\mathrm{m})$

$v($ air $)=$ velocity of air at inlet duct $\left(\mathrm{m}^{-\mathrm{s}^{-1}}\right)$

Mass flow rate of air (m) can be calculated by using the following formula:

$$
\dot{\mathrm{m}}=\rho \mathrm{m} * \mathrm{~V}
$$

$\rho \mathrm{m}=$ air density (mixture of dry air and vapour) $\left(\mathrm{kg} \cdot \mathrm{m}^{-3}\right)$

$$
\rho \mathrm{m}=\rho \mathrm{a}+\rho \mathrm{w}
$$

$$
\rho \mathrm{a}=\frac{\mathrm{Pa}}{\mathrm{Ra} * \mathrm{~T}} \rho \mathrm{w}=\frac{\mathrm{Pw}}{\mathrm{Rw} * \mathrm{~T}}
$$

$\rho \mathrm{a}=$ density of dry air $\left(\mathrm{kg} \cdot \mathrm{m}^{-3}\right)$

$\rho \mathrm{w}=$ density of vapour $\left(\mathrm{kg} \cdot \mathrm{m}^{-3}\right)$

$\mathrm{T}=$ temperature of dry air $\left({ }^{\circ} \mathrm{C}\right)$

4. Enthalpy of Moist Air: The moist air is mixture of dry air and water vapour, so enthalpy of moist air can be evaluated as: 


\section{International Journal of Science and Research (IJSR) \\ ISSN (Online): 2319-7064}

Index Copernicus Value (2013): 6.14 | Impact Factor (2015): 6.391

$\mathrm{h}=\mathrm{h}_{\mathrm{a}}+\omega \cdot \mathrm{h}_{\mathrm{w}}$

$\mathrm{h}_{\mathrm{a}}=$ enthalpy of dry air $(\mathrm{kJ} / \mathrm{kg})$

$\mathrm{h}_{\mathrm{w}}=$ specific enthalpy of water vapour $(\mathrm{kJ} / \mathrm{kg})$

$\mathrm{h}_{\mathrm{a}}=\mathrm{C}_{\mathrm{pa}} * \mathrm{~T}$

$\mathrm{h}_{\mathrm{w}}=\mathrm{h}_{\mathrm{go}}+\mathrm{C}_{\mathrm{ps}} * \mathrm{~T}$

$\mathrm{h}_{\mathrm{go}}=$ specific enthalpy of saturated water vapour at $\left(0^{\circ} \mathrm{C}\right)$, its value can be taken as $(2500 \mathrm{~kJ} / \mathrm{kg})$.

In temperature range of $\left(0\right.$ to $\left.60^{\circ} \mathrm{C}\right)$, the mean value of the specific heat of dry air $\left(\mathrm{C}_{\mathrm{pa}}\right)$ can be taken as $(1.005 \mathrm{~kJ} / \mathrm{kg} . \mathrm{K})$ and the specific heat of water vapour $\left(\mathrm{C}_{\mathrm{pa}}\right)$ can be taken as $(1.88 \mathrm{~kJ} / \mathrm{kg} . \mathrm{K})$ then the specific enthalpy of moist air (h) is given by:

$$
\mathrm{h}=1.005 * \mathrm{~T}+\omega *(2500+1.88 * \mathrm{~T}) \ldots \ldots . .(\mathrm{kJ} / \mathrm{kg})
$$

5. Heat Loss By Air: When a moist air passing through a cooling or heating medium, it will lose or gain heat (Q) That means there is a change in its state of temperature and content of water vapour (a change in the humidity ratio) It can be calculated as:

$$
Q=\dot{\mathrm{m}}^{*}\left(\mathrm{~h}_{2}-\mathrm{h}_{1}\right)
$$

$\mathrm{h} 1$ = enthalpy of inlet moist air $(\mathrm{kJ} / \mathrm{kg})$

$\mathrm{h} 2$ = enthalpy of outlet moist air $(\mathrm{kJ} / \mathrm{kg})$

Thus, the heat loss of air flow rate passing through a cooling system can be evaluated as:

$\mathrm{Q}=\dot{\mathrm{m}}\left\{1.005 *\left(\mathrm{~T}_{2}-\mathrm{T}_{1}\right)+2500 *\left(\omega_{2}-\omega_{1}\right)+1.88 *\left(\omega_{2} *\right.\right.$ $\left.\left.\mathrm{T}_{2}-\omega_{1} * \mathrm{~T}_{1}\right)\right\}$

And to calculate the average heat removed $\left(\mathrm{Q}_{\mathrm{av}}\right)$ during any time of cooling cycle, the trapezoidal rule can be used which states below:

$$
\mathrm{Qav}=\frac{\Delta t}{t c} *\left(\frac{Q 1+Q n}{2}+Q 2+Q 3+\cdots \ldots+Q n-1\right)
$$

$\Delta t=$ time interval (minutes)

tc $=$ time period of cooling (minutes)

\section{Results}

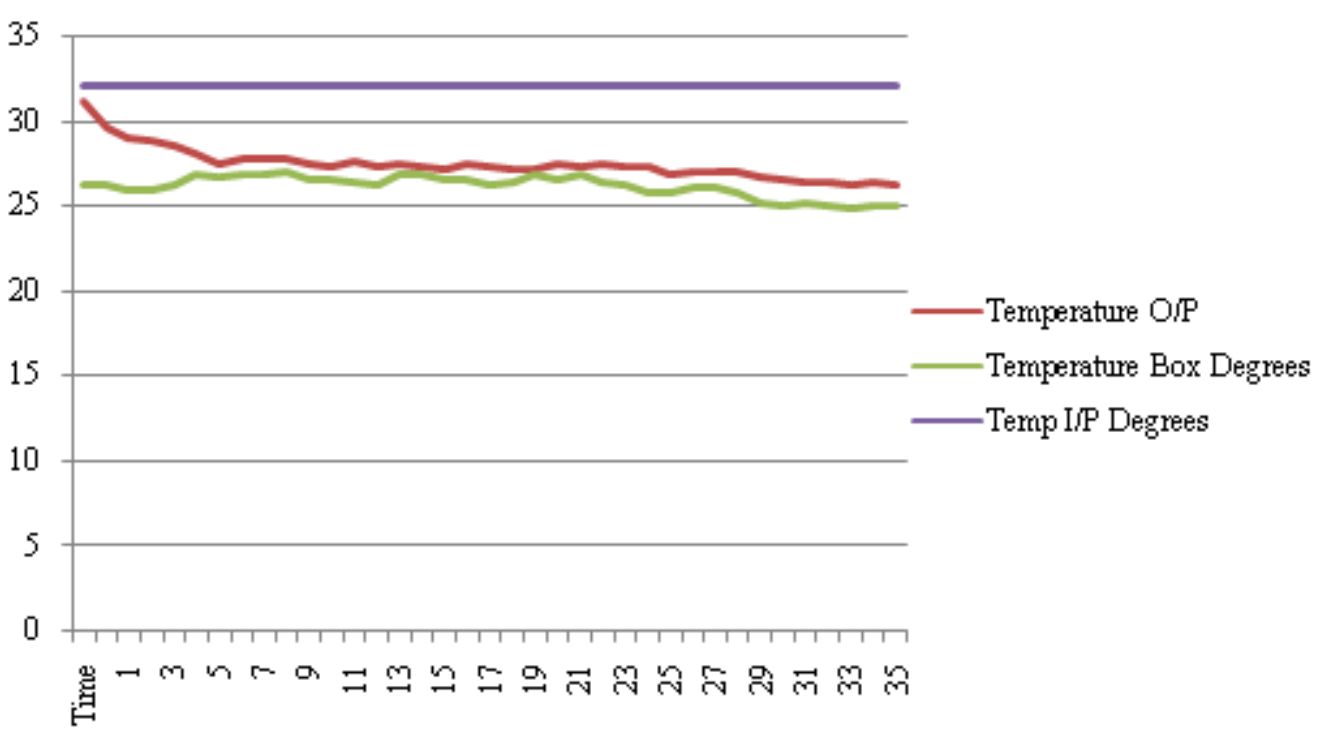

Graph 1: Temperatures vs. Time

Surrounding temperature remained constant at 32 degrees the box temperature initially was 26.3. It was observed that initial rate of cooling was high for first 8 minutes; in the same time there was a small increase in the box temperature. Thereafter, it was observed that the box temperature remained roughly constant with minute changes for the next
20 minutes. In the same duration the output temperature decreased at a lower rate than that observed initially. In the last 6 minutes of experiment both the box temperature and the output temperature decreased at a similar rate. 


\section{International Journal of Science and Research (IJSR) \\ ISSN (Online): 2319-7064}

Index Copernicus Value (2013): 6.14 | Impact Factor (2015): 6.391

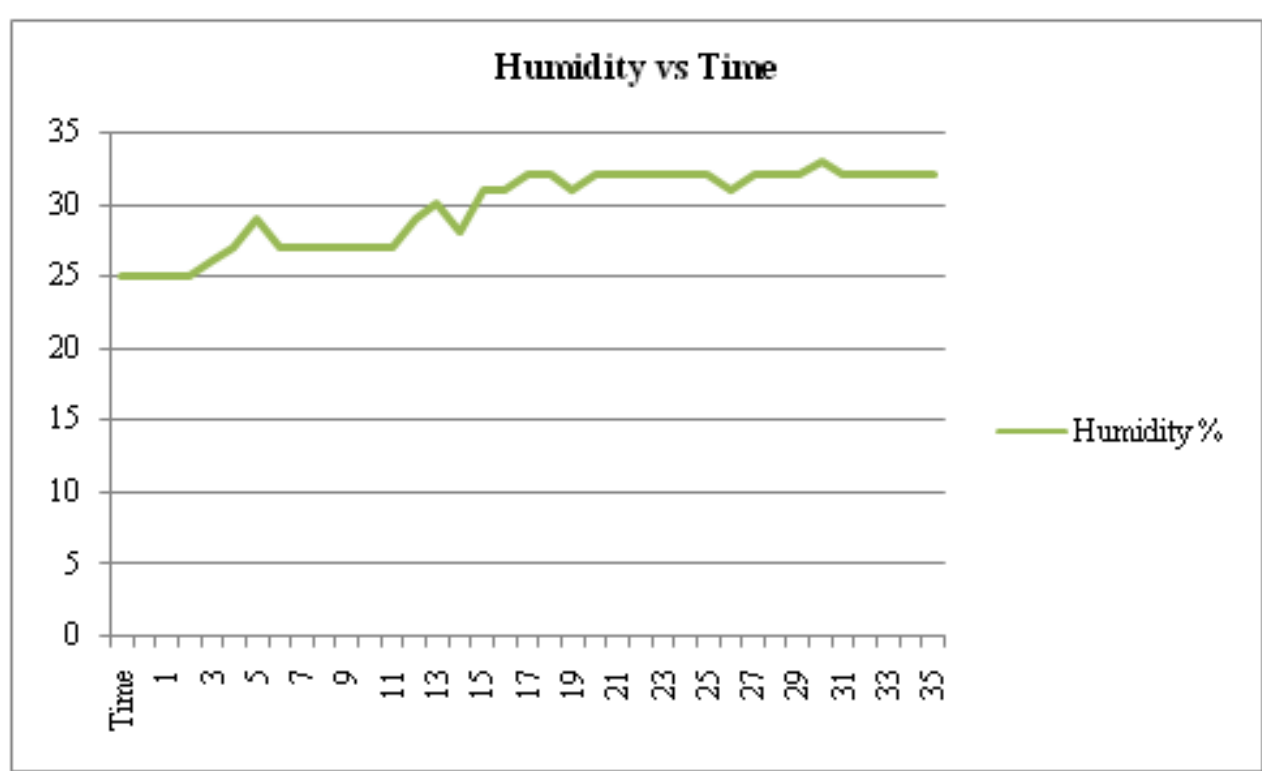

Graph 2: Humidity v/s Time

It was observed that the relative humidity increased at a rapid rate initially and at about twentieth minute the rate of increase of humidity started to become constant.

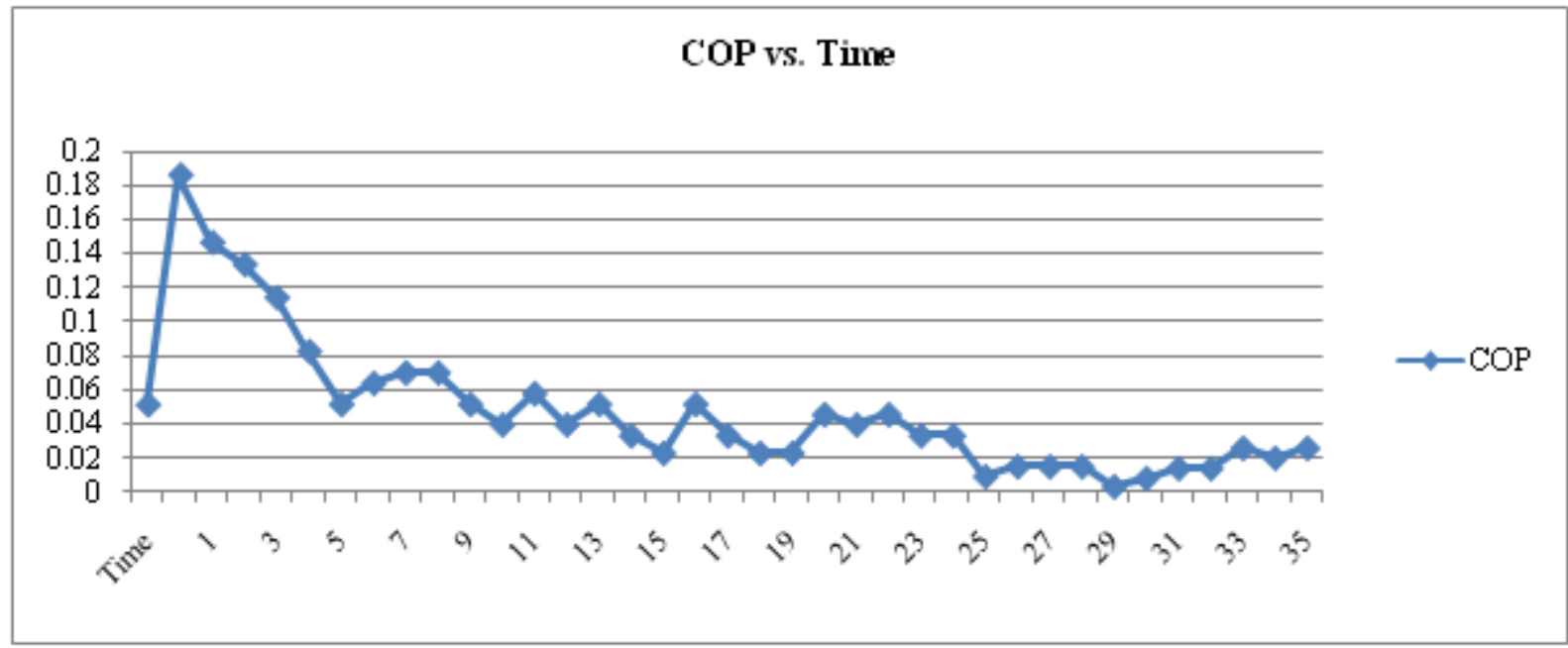

Graph 3: COP v/s Time

It was observed that in the first four minutes of the experiment, the COP increased at a rapid rate owing to a sudden fall in the output temperature. Thereon, the COP decreased at roughly a constant rate, and finally becoming constant towards the end of the experiment.

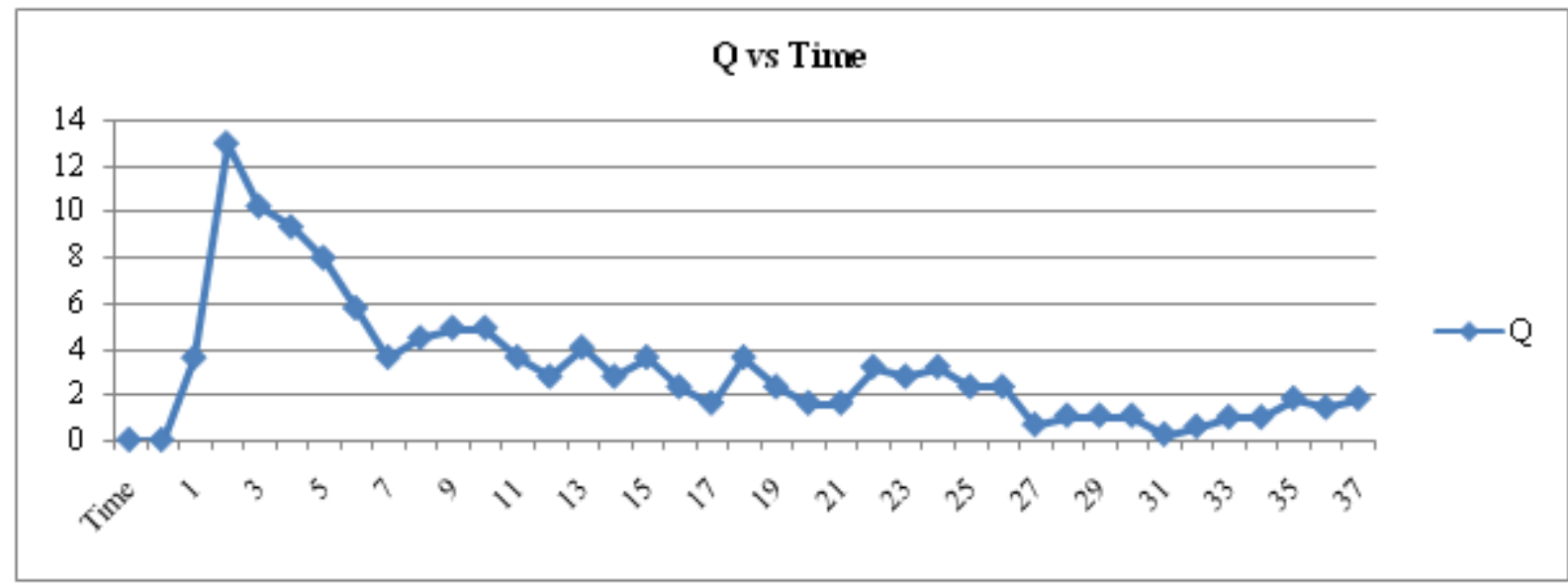

Graph 4: Q v/s Time

Volume 5 Issue 4, April 2016

www.ijsr.net 


\section{International Journal of Science and Research (IJSR) \\ ISSN (Online): 2319-7064 \\ Index Copernicus Value (2013): 6.14 | Impact Factor (2015): 6.391}

Similar to the COP there was a rapid increase in the heat transferred from the surrounding air to the Pykrete in the initial stages. And afterwards the heat transfer rate follows a similar trend to that of COP.

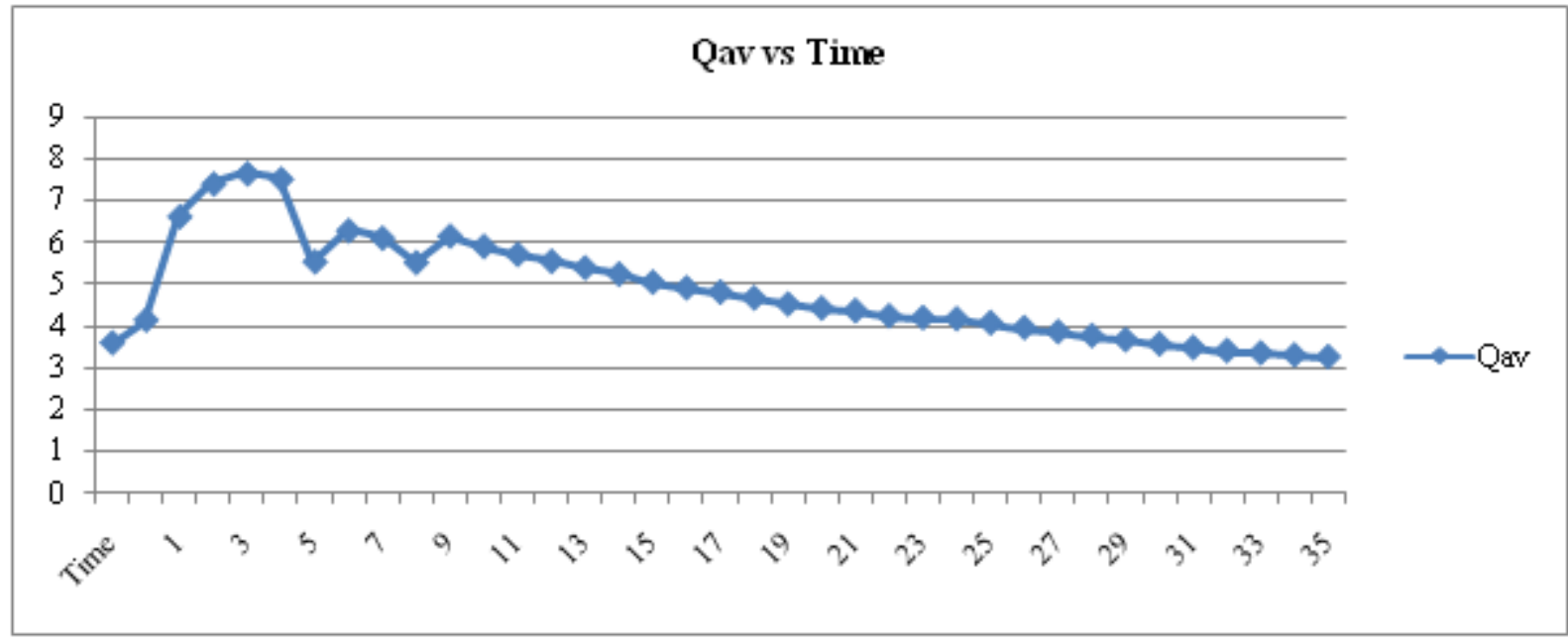

Graph 5: Qav v/s Time

The average heat transfer rate for the first four minutes was very high and thereafter it was observed that it decreased at a constant rate.

\section{Conclusion}

The experiment's procedure was carried out to study the performance of a model Thermal Energy Storage System. The measuring values for the inlet, outlet, box and Pykrete surface temperatures, relative humidity, dew point temperature and the power consumed by the working fan were measured by using Pykrete block of dimensions $(17.3 * 17.3 * 19.3 \mathrm{cc})$ to study the effect on performance.

Encouraging results were obtained in this paper where it was found that performance of using the Pykrete based Thermal Energy Storage System is effective in which the coefficient of performance (COP) is comparable to a conventional Ice based Thermal Energy Storage System. The results showed that the COP for higher air flow rate is lower than the COP for lower air flow rate due to lower power consumed by the system. And the outlet temperature for the higher air flow rate is higher than the outlet temperature for the lower air flow rate due to the more time of contact between the air and the Pykrete block. Since the Pykrete block melts at a very slow rate as compared to ice, a sustained cooling can be achieved for a longer duration as compared to ice based systems. The mass Pykrete required to attain a given amount of cooling effect is more than ice, but the time required for the same mass to melt is very high for Pykrete. Hence, a given amount of cooling can be achieved without refreezing the Pykrete block as is the case with ice.

\section{Future Scope}

1) By using Solar Intermittent Cooling, the electrical energy required to freeze the Pykrete block can be theoretically reduced to zero.

2) By changing the water to sawdust ratio, we can achieve different stable surface temperatures of Pykrete can be achieved and by selecting the appropriate mixture can be used according to the requirement.

\section{References}

[1] Fluid properties calculator, http://www.mhtl.uwaterloo.ca/old/onlinetools/airprop/ai rprop.html

[2] Heat and Mass Transfer, by Er. R.K.Rajput, ISBN: 81219-2617-3, Fifth revised edition reprint (2013)

[3] Mohammed Hadi Ali "Simple Domestic Air Conditioning by using the Ice Thermal Storage Capacity" ISSN 2250-3005 Paper Index 03.3005/031103013020

[4] Robert E. Wilson, Peter B. S. Lissaman, "Natural Refrigeration; "National Science Foundation, 1974.

[5] Numerical Methods, by B.S. Grewal, ISBN: 978-817409-248-9, Ninth Edition (2010)

[6] Refrigeration and Air Conditioning, by R.S.Khurmi, J.K.Gupta, ISBN: 81-219-2781-1, Fifth revised edition reprint (2014)

[7] Wikipedia, https://en.wikipedia.org/wiki/Pykrete

\section{Author Profile}

Alisha Vijay Supekar, B.E. Mechanical Engineering, Sinhgad Academy of Engineering, Pune

Divyashree Prasad Deore, B.E. Mechanical Engineering, Sinhgad Academy of Engineering, Pune

Sarthak Sharma, B.E. Mechanical Engineering, Sinhgad Academy of Engineering, Pune 